\title{
ENERGETIC VALORIZATION OF USED TIRES BY PYROLYSIS: EFFECT OF CATALYSTS ON BIOFUEL
}

\author{
REJEB Hiba ${ }^{1,{ }^{*},}$ BERRICH BETOUCHE Emna ${ }^{2}$, CHAHBANI Mohamed Hachemi $^{1}$ \\ ${ }^{1}$ Laboratory: Process Engineering \& Industrial Systems (LR11ES54), University of Gabes, 6072 Gabes, Tunisia. \\ ${ }^{2}$ GEPEA- CNRS UMR 6144, IMT Atlantique, Nantes, 44000. France
}

\begin{abstract}
Waste tires represent a disposal problem, environmental problem. To solve this problem and to upgrade this waste, several technologies are adopted such as pyrolysis. This technology produces a liquid that could replace other fuels. In this paper an experimental investigation is carried out to study the effect of the catalysts on biofuel. Two different percentages of catalysts have been used i.e. $10 \%$ and $20 \%$. Experiments were carried out in a semi-batch reactor under atmospheric pressure. The properties of the products measured are the viscosity, the gross calorific value and the acid value. Identification of gas and liquid products is made by GC and GC-MS respectively. It is found that the waste tires allow obtaining a liquid yield equal 30.53 wt. $\%$ and is the same with $20 \%$ of the catalysts but it increases to 32.77 wt. $\%$ with $10 \%$ of catalysts. This liquid presents close characteristics to gasoline and kerosene.
\end{abstract}

\section{Introduction}

Wastes tires represent a disposal problem, to solve it, several technologies are adopted such as pyrolysis. Two to three billion used tires are approximately in landfills and stockpiles across the United States, and each year, one scrap tire per person is generated[1].

The pyrolysis of waste used tires has been studied and reported in international literature. Several results encouraging have been obtained at different scales while using different technologies, either using different conditions. Several technologies have been developed for the pyrolysis of wastes tires. Fixed, batch rector $[2,8]$, fixed bed batch reactor $[3,4,5]$, internal fire tubes [6] and fluidized bed [7].

Aydin and al (2012) used waste tires without steel and fabric, in a fixed bed reactor in nitrogen over the temperature range of $400-700{ }^{\circ} \mathrm{C}$. They found that the oil yield increased from $31 \mathrm{wt} \%$ at $400{ }^{\circ} \mathrm{C}$ to $40 \mathrm{wt} . \%$ at 500 ${ }^{\circ} \mathrm{C}$. They investigated the influence of nitrogen flow rate on product yield and found only negligible differences in yield.

Williams et al. (1998) investigated the pyrolysis of waste tires, in a large batch reactor, with $2{ }^{\circ} \mathrm{C} / \mathrm{min}$ heating rate, using 1 ton of whole and shredded waste tire, have reported lower yields of oil $20.9 \mathrm{wt} . \%$ oil $(24.0 \mathrm{wt} . \%$ oil, corrected for steel) and $23.9 \mathrm{wt} . \%$ gas for pyrolysis temperature of $950^{\circ} \mathrm{C}$.

The objective of this work is to study the pyrolysis of waste tires at a heating rate $10{ }^{\circ} \mathrm{C} / \mathrm{min}$ and a $\mathrm{N}_{2}$ flow rate $\mathrm{Q}_{\mathrm{N} 2}=20 \mathrm{ml} / \mathrm{min}$ with different percentages of the ZSM5. The maximum temperature was set to $500^{\circ} \mathrm{C}$. In this case, the resistance is used at its maximum power, the time of heating between $250^{\circ} \mathrm{C}$ and $500^{\circ} \mathrm{C}$ is limited. In this case, the heating procedure is fluctuating up and down to control and equilibrate between the time and the temperature till arriving to $500^{\circ} \mathrm{C}$. The temperatures $250^{\circ} \mathrm{C}$ and $500^{\circ} \mathrm{C}$ have been chosen depending on the thermo-gravimetric analysis (TG) results. An inert gas current has been used during the pyrolysis, the system was purged with a high flow rate of $\mathrm{N}_{2}$ before the beginning of heating. Thus, volatiles leave reactor under the effects of thermal expansion and evaporation.

The temperatures $250^{\circ} \mathrm{C}$ and $500^{\circ} \mathrm{C}$ have been chosen depending on the thermo-gravimetric analysis (TG) results. The heating rate $\beta=10^{\circ} \mathrm{C} / \mathrm{min}$ and the flow rate $\mathrm{Q}_{\mathrm{N} 2}=20 \mathrm{ml} / \mathrm{min}$.

\section{Experimental methods}

\subsection{Materials}

The raw materials tested in this study are powders of waste tires from passenger cars that have been brought from a

\footnotetext{
* Corresponding author: rejebhiba@gmail.com
} 
WT Collection Company in France. The pieces were not shredded and contained all reinforced materials (wires, fibers). Tires powder dimensions ranged between $1 \times 1 \times 1$ $\mathrm{mm}^{3}$ and $2 \times 3 \times 1 \mathrm{~mm}^{3}$.

We would use small amounts of catalyst to achieve a high rate of yield production.

Catalysts are in the form of fine divided solid having a high specific surface.

Often, the use of a support allows limitation of powder agglomeration, thereby providing more stability for catalysts. Zeolite (ZSM-5) was used in this work as catalyst with different percentages.

Tires powders are very heterogeneous in size. They have been characterized and the results are presented in Table 1. The elemental analysis has been done on a C, H, N, S-O.

Table 1. Characterization of used tires.

\begin{tabular}{|c|c|c|c|c|c|c|}
\hline \multicolumn{5}{|c|}{ Elemental analysis (wt.\%) } & \multirow{2}{*}{$\begin{array}{c}\text { Ash } \\
\text { (wt.\%) }\end{array}$} & \multirow{2}{*}{$\begin{array}{c}\text { GCV } \\
(\mathrm{MJ} / \mathbf{k g})\end{array}$} \\
\hline $\mathrm{N}$ & $\mathrm{C}$ & $\mathrm{H}$ & $\mathrm{O}$ & $\mathrm{S}$ & & \\
\hline 0,47 & 80,82 & 6,79 & - & 1,11 & 11 & 32,572 \\
\hline
\end{tabular}

\subsection{Pyrolysis reactor}

The experimental setup used in this paper is shown in Fig. 1. The fixed bed reactor (6) has been used in this experiment. This reactor has as dimensions $: 17 \mathrm{~cm}$ diameter and $17 \mathrm{~cm}$ height cylindrical. Stainless steel, external electrical wall heated the reactor. It was purged using a high nitrogen (1) flow for 4-6 min before the beginning of each experiment to make sure that the system is filled with inert gas and no oxidation process will take place (pyrolysis).

This is verified by gas analysis at the end of purging by a micro GC (the percentage of the oxygen is less than $1 \%$ or else we should do another purging).

The pyrolysis experiments were carried out in a batch reactor under atmospheric pressure.

The produced volatiles are evaporated out of the reactor into a water-cooled counter-current condenser (9) (in the range $\left[15-20^{\circ} \mathrm{C}\right]$ ), where liquid fraction is condensed in the receiving flask.

The gases are analyzed by a micro GC instrument in order to identify the gas composition. Gas samples are taken each 5-10 min and in which an observed phenomen (bollard, the appearance of liquid, changes in the color of the liquid, peak of TG ....).

Heating was controlled via an external electrical heater (5) and temperature inside the reactor was monitored using three thermocouples $\left(\mathrm{T}_{0}, \mathrm{~T}_{1}, \mathrm{~T}_{2}\right)$.

Three thermocouples are attached to the reactor, the first one is located in the heating up resistance, the second one in the bottom, and the third one in the middle (central point). The first thermocouple measures the set point temperature, the second one measures the temperature of the wall and the third one measures the temperature inside the reactor. The reactor is heated up to $500^{\circ} \mathrm{C}$, then the temperature is stabilized at $500^{\circ} \mathrm{C}$ (it is chosen depending on the results of TG, condensation of the fluid, energy ...). The acquisition device (4) registered the values of temperatures evolution inside the reactor $\left(T_{0}, T_{1}, T_{2}\right)$ and the reference temperature $(\mathrm{T})$, allowed the control of thermal profile all along the process.

The collected liquid in the receiving flask is characterized (viscosity, density, Gross Calorific Values (GCV) and GC-MS). The remaining solid at the bottom of the reactor (coal) is characterized (Gross Calorific Values (GCV), mass, the yield of the solid...).

\subsection{Measuring equipments}

Elementary analysis has been done using FLASH EA 1112 series CHNS-O analyzer with limit of detection $0.2 \%$ for each element and sample weight range is [0.5-1] mg.

Thermogravimetric instrument brand is SETARAM Setsys Evolution 16/18 TGA-DSC. Sample weight range [4-200] $\mathrm{mg}$, max temperature is $1700^{\circ} \mathrm{C}$ and inert gas (nitrogen) flow range is [4-200] $\mathrm{ml} / \mathrm{min}$.

Gaseous products $\left(\mathrm{H}_{2}, \mathrm{CH}_{4}, \mathrm{C}_{2} \mathrm{H}_{2}, \mathrm{C}_{2} \mathrm{H}_{4}, \mathrm{C}_{2} \mathrm{H}_{6}, \mathrm{C}_{3} \mathrm{H}_{6}\right.$, $\mathrm{C}_{3} \mathrm{H}_{8}, \mathrm{C}_{4} \mathrm{H}_{10}, \mathrm{CO}, \mathrm{CO}_{2}, \mathrm{O}_{2}$ and $\mathrm{N}_{2}$ ) were analyzed using a Micro-GC: Agilent technologies 3000A with a thermal conductivity detector.

GCV has been obtained using Parr 6200 calorimeter; upper limit of detection $55 \mathrm{~kJ} / \mathrm{g}$. Viscosity was measured using AND Vibro viscometer SV-10, with measuring range $0.3-10,000 \mathrm{mPa}$.s. In addition, GC-MS analyses were performed using a Perkin Elmer gas chromatograph Clarus 680 connected to a mass spectrometer Perkin Elmer Clarus 600S operating with electron-ionization at $70 \mathrm{eV}$.

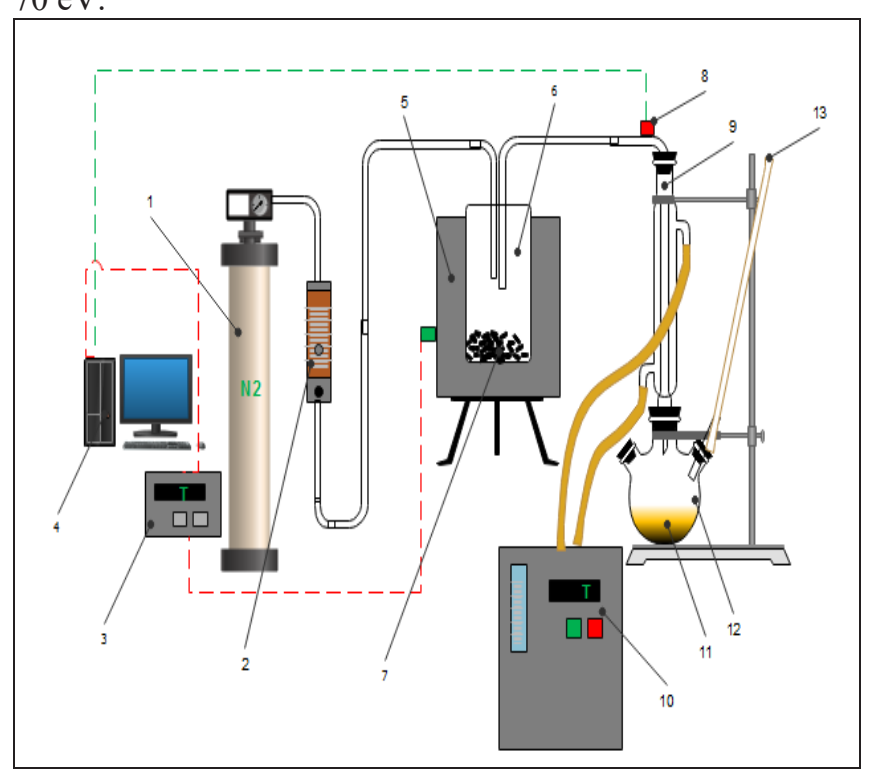

Fig. 1. Experimental set-up.

1: Nitrogen, 2: flow meter, 3: acquisition software, 4: acquisition software, 5 : heating up resistance, 6 : reactor, 7 : row material, 8: pressure sensor, 9: condenser, 10: cooled water, 11: liquid, 12: receiving flask, 13: gas outlet. 


\section{Experimental methods Results and discussion}

\subsection{Analysis of liquid and solid by-products}

Fig. 2 shows the values of GCV of solids and liquids. It can be concluded that by adding $10 \%$ of ZSM5 and $20 \%$ of ZSM5, the pyrolysis reactions were effective in terms of conversion rate and temperature of the first appearance of the liquid.

Increasing the catalyst percentage reduces the solid yield. Fig 2 shows that when the \% of ZSM5 is increased, the GCV of the solid is reduced but not that of the liquid. It was noticed that the liquid produced during pyrolysis of used tires in the presence of ZSM5 is lighter than the liquid obtained in the absence of ZSM5, which confirms the difference obtained in calculating GCV (the Gross Calorific Value increases with the carbon chain). Furthermore, pyrolysis of tires only gives a viscous liquid of darker color, while the adding of ZSM5 gives a more dense and a clearer liquid.

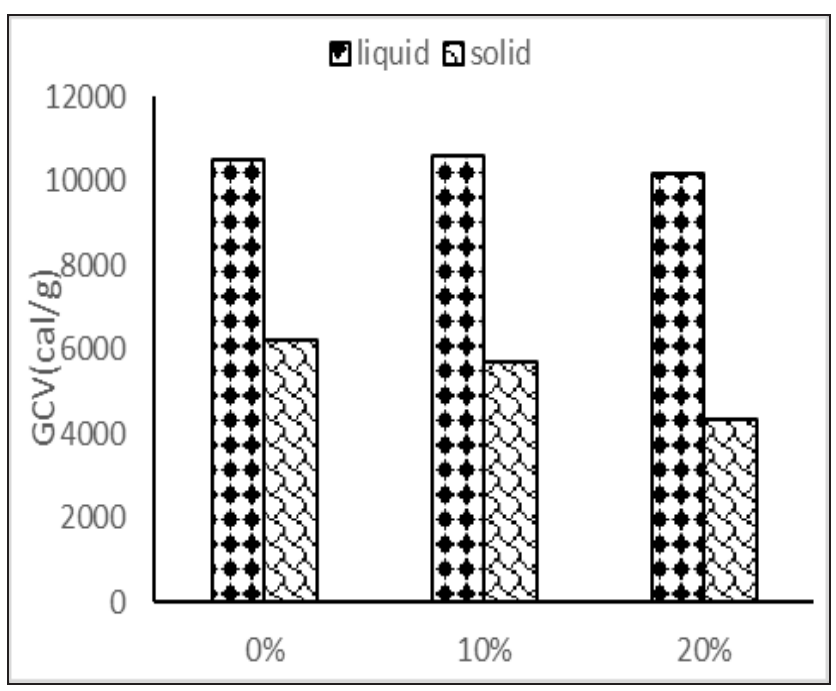

Fig. 2. The Gross Calorific Values (GCV) of solid and liquid by-products.

\subsection{Analysis of gaseous by-products}

Using micro $\mathrm{GC}$ instrument, we determine the gas compounds: $\left(\mathrm{H}_{2}, \mathrm{CH}_{4}, \mathrm{C}_{2} \mathrm{H}_{2}, \mathrm{C}_{2} \mathrm{H}_{4}, \mathrm{C}_{2} \mathrm{H}_{6}, \mathrm{C}_{3} \mathrm{H}_{6}, \mathrm{C}_{3} \mathrm{H}_{8}\right.$, $\mathrm{C}_{4} \mathrm{H}_{10}, \mathrm{CO}, \mathrm{CO}_{2}, \mathrm{O}_{2}$ and $\mathrm{N}_{2}$ ). $\mathrm{CO}$ and $\mathrm{CO}_{2}$ appear at the beginning when the temperature is in the rang $\left[250{ }^{\circ} \mathrm{C}\right.$ $350{ }^{\circ} \mathrm{C}$ ], this may be due to degradation of some additives containing oxygen (rubber structure does not contain oxygen). It was found that the main components of the generated gases are hydrogen $\left(\mathrm{H}_{2}\right)$ and methane $\left(\mathrm{CH}_{4}\right)$ all over reaction duration. Fig. 3 shows the hydrogen concentration of pyrolysis experiment with different percentages of ZSM 5.
It was noticed that ZSM5 affects the percentage of gas produced. For example, hydrogen produced when only tires are used is higher than hydrogen produced in the presence of ZSM5.

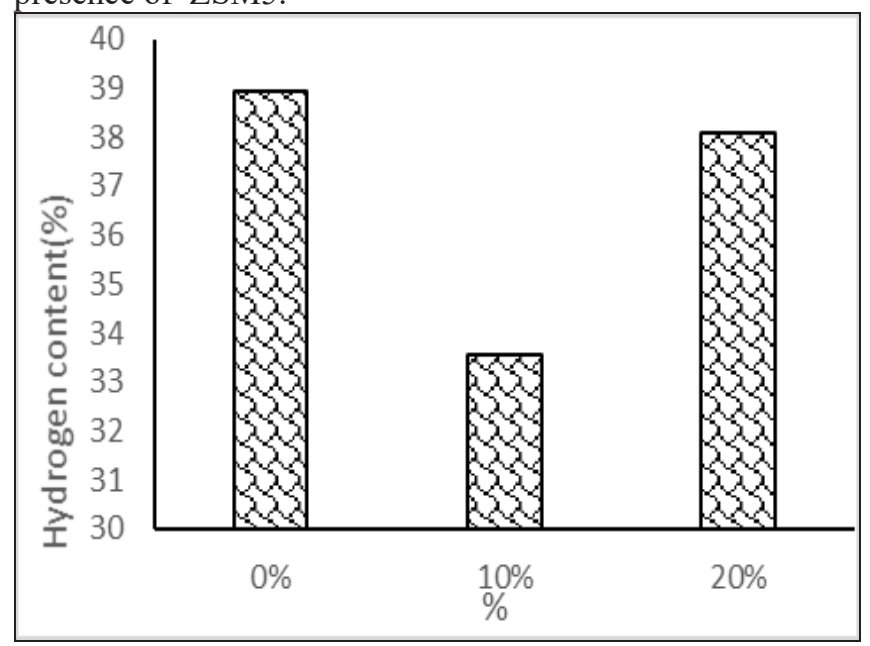

Fig. 3. Hydrogen concentration of pyrolysis experiment with different percentages of ZSM5.

\subsection{Influence of catalyst on the pyrolysis by- product yields}

It was noticed that ZSM5 has an effect on the conversion rate and the percentage of gas produced.

A high percentage of ZSM5 induced the higher percentage of gas.

For the different percentages of catalyst ZSM5, It is found that the highest yield is obtained for the solid, it is followed by the liquid, the lowest yield is relative to the gas. The yield of the liquid increases when we have additives but not that of the solid.

Fig . 4 shows the variation of product yield.

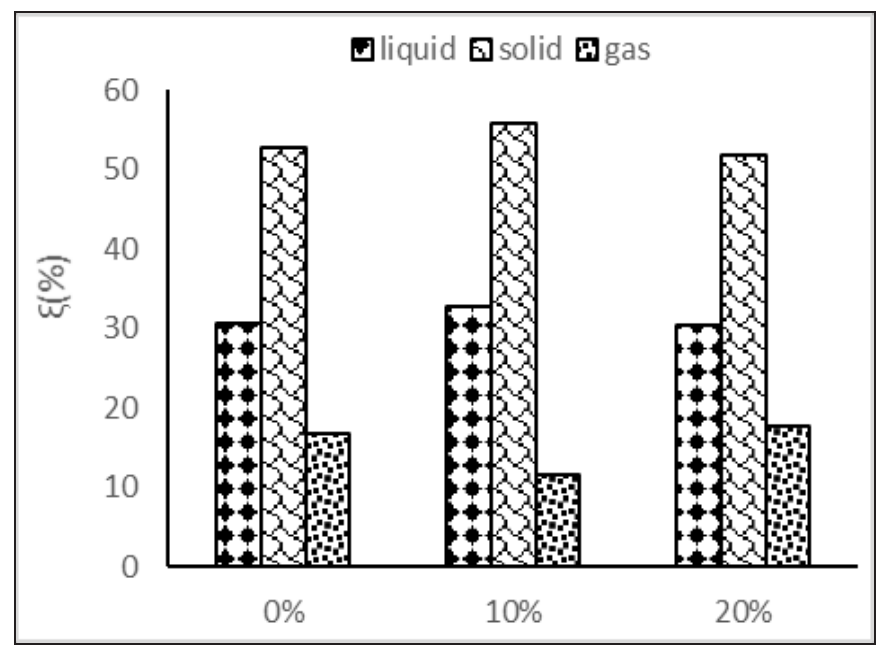

Fig. 4. The yields of by-products. 
The effects of this additive on the yield and physicochemical characteristics of liquid products are shown in Table 2 .

Table 1 shows that the GCVs of three liquid products were comparable, significant differences between their other characteristics were noticed.

\subsection{Comparison of the proprieties of the liquid}

Table 3 shows comparison between liquid products and some common fuels (gasoline, kerosene and diesel).
It can be noticed that for catalyst percentages of $20 \%$ and $0 \%$, we get a liquid comparable with diesel that has density and GCV in the verge but a different value for viscosity. For a catalyst percentage of $10 \%$, the liquid obtained has a higher value of density than the other liquids.

Table 1. Liquid products' characteristics with different $\%$ of catalyst.

\begin{tabular}{|c|c|c|c|c|c|c|c|}
\hline Experiment No. & \% catalyst & FR(ml/min) & $\boldsymbol{\beta}\left({ }^{\circ} \mathbf{C} / \mathbf{m i n}\right)$ & $\begin{array}{c}\text { Yield } \\
(\mathbf{w t} \%)\end{array}$ & $\begin{array}{c}\text { Density } \\
(\mathbf{k g} / \mathbf{l})\end{array}$ & $\begin{array}{c}\text { Viscosity } \\
(\mathbf{m P a s} \mathbf{a} \mathbf{4 0} \\
\circ \mathbf{C})\end{array}$ & $\begin{array}{c}\mathbf{G C V} \\
(\mathbf{M J} / \mathbf{k g})\end{array}$ \\
\hline 1 & 0 & 20 & 10 & 47.21 & 0.8036 & 0.91 & 43.867 \\
\hline 2 & 10 & 20 & 10 & 44.23 & 1.16 & 0.86 & 44.125 \\
\hline 3 & 20 & 20 & 10 & 48.26 & 0.856 & 1.07 & 42.605 \\
\hline
\end{tabular}

Table 2. Comparison between liquid products and some common fuels.

\begin{tabular}{|c|c|c|c|c|c|c|}
\hline \multirow{2}{*}{ Properties } & \multirow{2}{*}{ Gasoline } & \multirow{2}{*}{ Kerosene } & \multirow{2}{*}{ Diesel } & \multicolumn{3}{|c|}{ Pyrolytic oil } \\
\hline & & & & 1 & 2 & 3 \\
\hline Density (kg/m3) & $\begin{array}{c}743-751 \\
\left(\text { at } 20-30^{\circ} \mathrm{C}\right)\end{array}$ & $\begin{array}{c}760-767 \\
\text { (at } 20-30^{\circ} \mathrm{C} \text { ) }\end{array}$ & $870-1000$ & 803.64 & 1163.85 & 856.24 \\
\hline Flash point $\left({ }^{\circ} \mathrm{C}\right)$ & -46 & 38 & $38-58$ & - & - & - \\
\hline GCV (MJ/kg) & 47 & 46 & 45 & 43.867 & 44.125 & 42.605 \\
\hline $\begin{array}{c}\text { Viscosity (cP) at } 40 \\
{ }^{\circ} \mathrm{C}\end{array}$ & 0.41 & 1.7 & 3.35 & 0.91 & 0.86 & 1.07 \\
\hline
\end{tabular}

\section{Conclusions}

This work shows the effect of the percentage of catalyst on the pyrolysis of waste tires in terms of yield and composition of gas, liquid and solid.

Depending on $\%$ of the catalyst, pyrolysis products yields change. It is found that waste tires allow obtaining a liquid yield equal $30.53 \mathrm{wt} \%$ in the absence of catalyst. The same value of yield is obtained with $20 \%$ of catalyst. However, a value of $32.77 \mathrm{wt} . \%$ with $10 \%$ of catalyst has been obtained. The liquid produced presents close characteristics to gasoline and kerosene.

\section{KEYWORDS}

Waste tires, valorization, pyrolysis, biofuel.

\section{References}

1. Reisman, J. I., \& Lemieux, P. M.. Air emissions from scrap tire combustion. In Air emissions from scrap tire combustion. EPA. (1997)

2. Islam, M. R., Joardder, M. U. H., Hasan, S. M., Takai, K., \& Haniu, H. Feasibility study for thermal treatment of solid tire wastes in Bangladesh by using pyrolysis technology. Waste management, 31(9-10), 2142-2149. (2011).

3. Aydın, H., \& İlkılıç, C. Optimization of fuel production from waste vehicle tires by pyrolysis and resembling to diesel fuel by various desulfurization methods. Fuel, 102, 605-612. (2012).

4. Williams, P. T., Bottrill, R. P., \& Cunliffe, A. M. Combustion of tyre pyrolysis oil. Process safety and environmental protection, 76(4), 291-301. (1998).

5. Kar, Y. Catalytic pyrolysis of car tire waste using expanded perlite. Waste management, 31(8), 17721782. (2011). 
6. Islam, M. R., Joardder, M. U. H., Kader, M. A., \& Sarker, M. R. Valorization of solid tire wastes available in Bangladesh by thermal treatment. (2011).

7. Kaminsky, W., Mennerich, C., \& Zhang, Z. Feedstock recycling of synthetic and natural rubber by pyrolysis in a fluidized bed. Journal of Analytical and Applied Pyrolysis, 85(1), 334-337. (2009).

8. Alkhatib, R., Loubar, K., Awad, S., Mounif, E., \& Tazerout, M. Effect of heating power on the scrap tires pyrolysis derived oil. Journal of Analytical and Applied Pyrolysis, 116, 10-17. (2015). 